Check for updates

Cite this: RSC Adv., 2018, 8, 16603

\title{
A long-persistent phosphorescent chemosensor for the detection of TNP based on $\mathrm{CaTiO}_{3}: \mathrm{Pr}^{3+} \mathrm{aSiO}_{2}$ photoluminescence materials $\uparrow$
}

\author{
Fangfang $\mathrm{Li}^{\mathrm{a}}{ }^{\text {Fengyi Wang, }}{ }^{\mathrm{a}}$ Xuan $\mathrm{Hu},{ }^{\mathrm{a}}$ Baozhan Zheng, ${ }^{\mathrm{a}}$ Juan Du (D) *ab \\ and Dan Xiao (iD) *ab
}

\begin{abstract}
The detection of nitroaromatic explosives is important due to their strong explosive force and harmfulness in the environment, and for homeland security and public safety. Herein, a phosphorescence $\mathrm{CaTiO}_{3}: \mathrm{Pr}^{3+} \mathrm{aSiO}_{2}$ nanosensor was successfully developed for the sensitive and selective detection of 2,4,6-trinitrophenol (TNP). The red-emitting phosphorescent chemosensor $\mathrm{CaTiO}_{3}: \mathrm{Pr}^{3+} \mathrm{aSiO}_{2}$ possessed a long enough phosphorescence lifetime of $0.016 \mathrm{~s}$. The TNP induced phosphorescence quenching process of $\mathrm{CaTiO}_{3}: \mathrm{Pr}^{3+} \mathrm{eSiO}_{2}$ presented a wide linearity with TNP concentrations ranging from 0.5 to $100 \mu \mathrm{M}$, and the detection limit was found to be $20.6 \mathrm{nM}$. Furthermore, this sensor displayed a high selectivity toward TNP over other structurally similar compounds like 2,4,6-trinitrotoluene (TNT), 2,4dinitrotoluene (DNT), 4-nitrotoluene (NT), 2,4-dinitrophenol (DNP), 4-nitrophenol (NP) and phenol. This sensing system was successfully used in the test of TNP concentrations in water samples, and showed great potential for practical application.
\end{abstract}

Received 27th March 2018 Accepted 27th April 2018

DOI: $10.1039 / \mathrm{c} 8 \mathrm{ra02665c}$

rsc.li/rsc-advances these methods are complicated or time-consuming, and involve complex operation of expensive instruments, all of which will impede their widespread application. Photoluminescence (PL)based chemosensors have gained more attention because of their low instrumentation cost, short response time, high sensitivity and selectivity. ${ }^{21,22}$ On the other hand, when using an optical sensing technology, a large background fluorescence signal will cause a negative impact during detection process, ${ }^{23,24}$ Compared with fluorescent materials, phosphorescent materials can eliminate the interference from short-lived fluorescent background by using time-resolved technology, with added advantages of high luminescence efficiency, and good photo and thermal stabilities. ${ }^{25-27}$ Nevertheless, so far there are few reports about detecting nitroaromatic explosives by means of phosphorescence method.

In recent years, the photoluminescence materials of alkaline earth titanates doped with rare earth ions have attracted research interests due to their high chemical stability. ${ }^{28}$ Most titanates photoluminescence materials were widely used in the fields of emergency lighting, interior decoration, road signs and AC-LEDs. ${ }^{29-31}$ Among which, $\mathrm{CaTiO}_{3}: \mathrm{Pr}^{3+}$ photoluminescence materials became very popular due to its persistent afterglow phenomenon. $\mathrm{CaTiO}_{3}: \mathrm{Pr}^{3+}$ material has perovskite structure, when $\mathrm{Pr}^{3+}$ incorporates in $\mathrm{CaTiO}_{3}$ perovskite, it yields a single red emission, from the ${ }^{1} \mathrm{D}_{2}-{ }^{3} \mathrm{H}_{4}$ transition, due to the overlying inter-valence charge transfer that completely depopulates the ${ }^{3} \mathrm{P}_{0}$ state. ${ }^{32,33}$ Recently, $\mathrm{CaTiO}_{3}: \mathrm{Pr}^{3+}$ material has received more attention because of its good persistent characteristics with chromaticity coordinate close to the "ideal red", excellent
${ }^{a}$ College of Chemistry, Sichuan University, 29 Wangjiang Road, Chengdu 610064, China.E-mail:dujuanchem@scu.edu.cn; xiaodan@scu.edu.cn

${ }^{b}$ Key Laboratory of Green Chemistry and Technology, Ministry of Education, College of Chemistry, Sichuan University, Chengdu, Sichuan 610064, China

$\dagger$ Electronic supplementary information (ESI) available. See DOI: $10.1039 / \mathrm{c} 8 \mathrm{ra02665c}$ 
chemical/physical stability, and eco-friendliness. ${ }^{34,35}$ In order to gain a better performance, great efforts have been made to prepare the nano-sized $\mathrm{CaTiO}_{3}: \mathrm{Pr}^{3+}$ photoluminescence material, such as solid-state reaction, ${ }^{36}$ precipitation technique, ${ }^{37}$ sol-gel process ${ }^{38}$ and hydrothermal synthesis. ${ }^{39}$ As a persistent phosphorescent material, $\mathrm{CaTiO}_{3}: \mathrm{Pr}^{3+}$ has attracted considerable attention for various displays and signing applications in dark environments. However, until now, there were no attention to the determination of nitroaromatic explosives using $\mathrm{CaTiO}_{3}: \operatorname{Pr}^{3+}$.

In the present work, we prepared long-persistent redemitting $\mathrm{CaTiO}_{3}: \operatorname{Pr}^{3+}$ photoluminescence material under solid-state synthesis method. Because of its poor solubility in many solvents, the $\mathrm{CaTiO}_{3}: \mathrm{Pr}^{3+}$ nanoparticles should be functionalized to make it solvent-stable before utilization as a photoluminescence probe. Herein, the $\mathrm{CaTiO}_{3}: \mathrm{Pr}^{3+}$ nanoparticles can be uniformly dispersed in water via a facile strategy of coating a silica shell on the $\mathrm{CaTiO}_{3}: \mathrm{Pr}^{3+}$ surface to form a photoluminescence composite material, and presented an example of application of $\mathrm{CaTiO}_{3}: \mathrm{Pr}^{3+} @ \mathrm{SiO}_{2}$ nanoparticles for TNP detection. In this work, $\mathrm{CaTiO}_{3}: \mathrm{Pr}^{3+} @ \mathrm{SiO}_{2}$ nanoparticles displayed a high sensitivity toward TNP over other structurally similar compounds like 2,4,6-trinitrotoluene (TNT), 2,4-dinitrotoluene (DNT), 4-nitrotoluene (NT), 2,4-dinitrophenol (DNP), 4-nitrophenol (NP) and phenol. This assay can effectively detect TNP range from $0.5 \mu \mathrm{M}$ to $100 \mu \mathrm{M}$ with a detection limit of $20.6 \mathrm{nM}$. This method was also successfully used to analyze TNP in natural water samples.

\section{Experimental section}

\section{Chemicals}

Praseodymium oxide $\left(\operatorname{Pr}_{6} \mathrm{O}_{11}\right)$, 2,4,6-trinitrophenol (TNP), 2,4,6trinitrotoluene (TNT), 2,4-dinitrotoluene (DNT), 4-nitrotoluene (NT), 2,4-dinitrophenol (DNP), 4-nitrophenol (NP) and phenol were purchased from Aladdin (Shanghai, China); orthoboric acid $\left(\mathrm{H}_{3} \mathrm{BO}_{3}\right)$, titanium oxide $\left(\mathrm{TiO}_{2}\right)$, calcium nitrate tetrahydrate $\left(\mathrm{Ca}\left(\mathrm{NO}_{3}\right)_{2} \cdot 4 \mathrm{H}_{2} \mathrm{O}\right)$ were purchased from Chengdu Chemical Reagent Company (Chengdu, China); tetraethyl orthosilicate (TEOS), cyclohexane, $n$-hexanol, and Triton X-100 (TX-100) were purchased from Tianjin Reagent Plant (Tianjin, China). All the other chemicals were of analytical-reagent grade and used without further purification.

\section{Apparatus}

UV-visible spectra were measured on Hitachi U-2900 spectrophotometer equipped with a $1 \mathrm{~cm}$ quartz cell. Phosphorescence spectra were measured on Hitachi F-7000 spectrophotometer equipped with a $1 \mathrm{~cm}$ quartz cell. Scanning electron microscopy (SEM) images were recorded on a field emission Hitachi S4800 microscope (Japan) equipped with a Oxford energy-dispersive Xray (EDX) detector (UK) to perform the elemental mapping. Xray diffraction (XRD) measurement was acquired on a Tongda TD-3500 X-ray powder diffractometer (Liaoning, China) with $\mathrm{Cu}$ $\mathrm{K} \alpha$ radiation. Phosphorescence lifetime was measured on a Fluorolog-3 spectrofluorometer (Horiba JobinYvon) with a Spectra LED (280 nm, S-280, Horiba Scientific) as the excitation source and a picosecond photon detection module (PPD850, Horiba Scientific) as the detector. The Particle size were measured on a Malvern Nano ZS90 Zetasizer Nano instrument (Worcestershire, UK).

\section{Preparation of the $\mathrm{CaTiO}_{3}: \mathrm{Pr}^{3+}$ nanoparticles}

$\mathrm{CaTiO}_{3}: \mathrm{Pr}^{3+}$ were prepared by a solid-state synthesis method as described in the literature with a little modification. ${ }^{40} \mathrm{Pr}^{3+}$ was introduced in the form of $\operatorname{Pr}\left(\mathrm{NO}_{3}\right)_{3}$ by dissolving $\operatorname{Pr}_{6} \mathrm{O}_{11}$ into $\mathrm{HNO}_{3} \cdot \mathrm{Ca}\left(\mathrm{NO}_{3}\right)_{2} \cdot 4 \mathrm{H}_{2} \mathrm{O}, \mathrm{TiO}_{2}$, and $\mathrm{Pr}^{3+}$ were weighed according to the nominal compositions of $\mathrm{CaTiO}_{3}: x \operatorname{Pr}^{3+}(x=0 \%, 0.1 \%$, $0.4 \%$ and $1 \%$ ), and $3 \mathrm{wt} \% \mathrm{H}_{3} \mathrm{BO}_{3}$ was added as a flux, then they were mixed by ultrasonic cleaner at room temperature for $15 \mathrm{~min}$, the mixture was put into tube furnace to sinter at $900{ }^{\circ} \mathrm{C}$ for 1-5 h. At last, white powder samples $\mathrm{CaTiO}_{3}: \operatorname{Pr}^{3+}$ were gained.

\section{Synthesis of $\mathrm{CaTiO}_{3}: \mathrm{Pr}^{3+} @ \mathrm{SiO}_{2}$ nanoparticles}

Typically, $15 \mathrm{~mL}$ cyclohexane, $3.4 \mathrm{~mL}$ Triton X-100 and 3.6 mL 1hexanol are mixed uniformly, after stirring for 5 minutes, a certain concentration of as-prepared $\mathrm{CaTiO}_{3}: \mathrm{Pr}^{3+}$ nanoparticles $(50 \mathrm{mg})$ and $300 \mu \mathrm{L}$ deionized water were added to a beaker under stirring to form a w/o microemulsion. Then 100 $\mu \mathrm{L}$ tetraethyl orthosilicate (TEOS) and $100 \mu \mathrm{L}$ ammonia aqueous solution were added to the microemulsion and the sample was mechanically stirred for $24 \mathrm{~h}$ at room temperature. To separate the particles, ethanol was added to break the microemulsion. The resulting nanocomposites were centrifuged and washed repeatedly with water and ethanol and then dried in vacuum at $40{ }^{\circ} \mathrm{C}$ overnight.

\section{Results and discussion}

\section{Preparation and characterization of $\mathrm{CaTiO}_{3}: \mathrm{Pr}^{3+} @ \mathrm{SiO}_{2}$ nanoparticles}

As mentioned previously, the strong phosphorescence $\mathrm{CaTiO}_{3}: \mathrm{Pr}^{3+}$ nanoparticles were prepared by solid phase method. We tested the phosphorescence intensity of $\mathrm{CaTiO}_{3}$ :$\mathrm{Pr}^{3+}$ with different mole ratios of $\mathrm{Pr}^{3+}$ and calcination time. Fig. S1A $\dagger$ exhibited the phosphorescence spectra of $\mathrm{CaTiO}_{3}$ :$x \operatorname{Pr}^{3+}(x=0-1 \%)$ samples upon $315 \mathrm{~nm}$ excitation. The sample had no phosphorescence emission intensity at $x=0$, and the
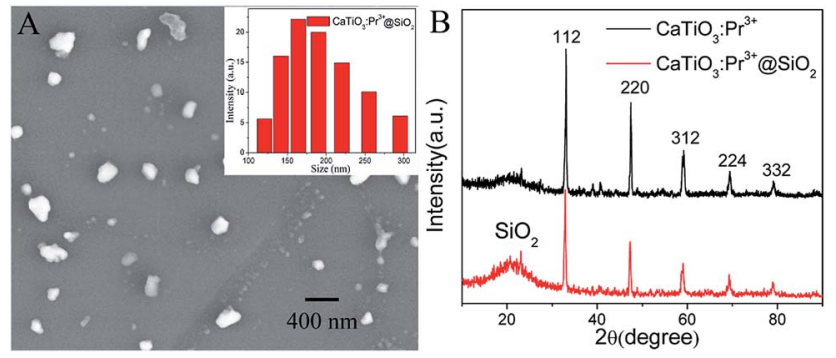

Fig. 1 (A) SEM image of $\mathrm{CaTiO}_{3}: \mathrm{Pr}^{3+} \mathrm{CSiO}_{2}$ nanoparticles, (inset: size distribution of $\mathrm{CaTiO}_{3}: \mathrm{Pr}^{3+} \mathrm{aSiO}_{2}$ nanoparticles), (B) XRD pattern of $\mathrm{CaTiO}_{3}: \mathrm{Pr}^{3+}$ and $\mathrm{CaTiO}_{3}: \mathrm{Pr}^{3+} \mathrm{aSiO}_{2}$ samples. 

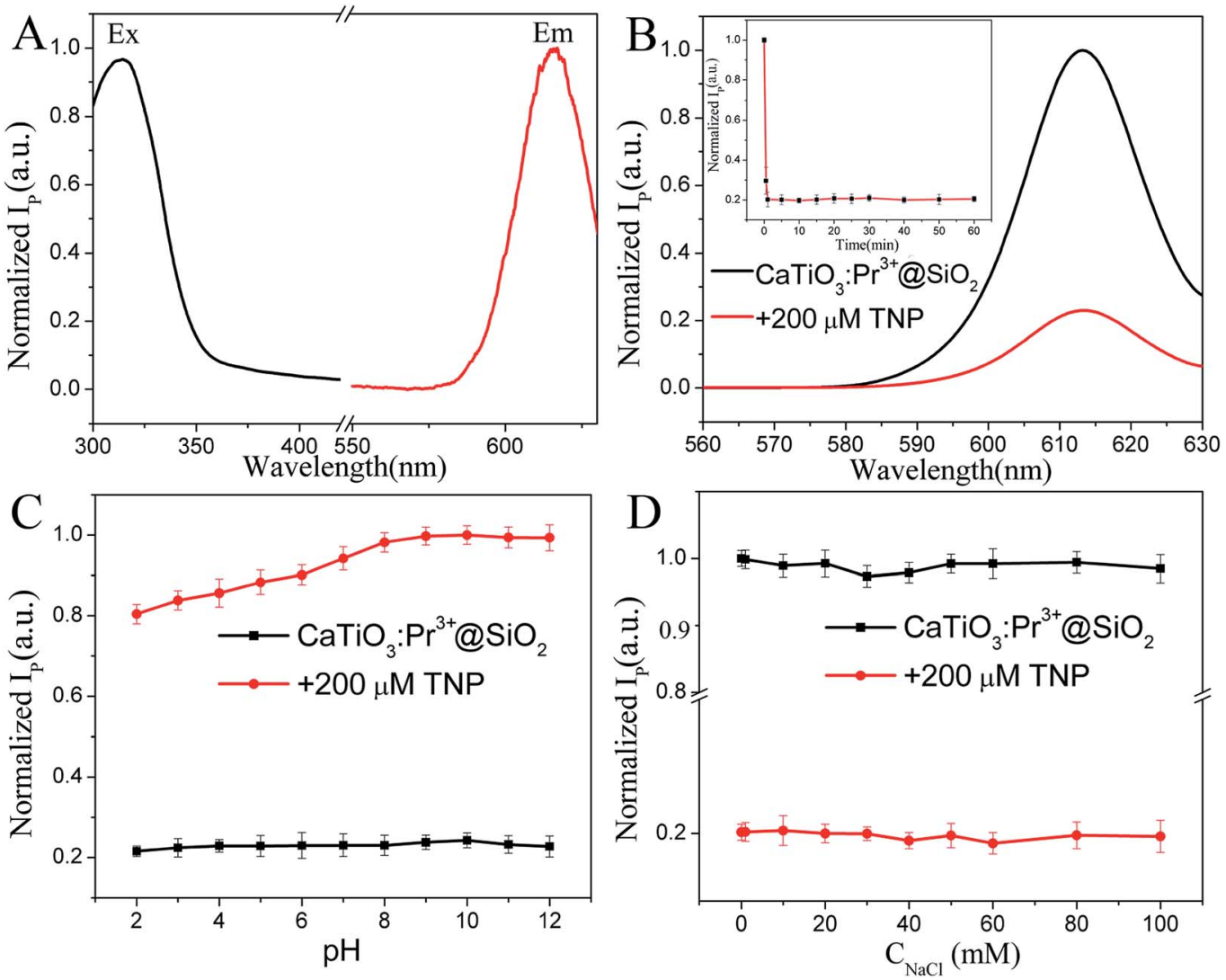

Fig. 2 (A) Phosphorescence excitation (Ex) and emission spectra (Em) of $\mathrm{CaTiO}_{3}: \mathrm{Pr}^{3+}\left(\mathrm{aSiO}_{2}\left(30 \mu \mathrm{g} \mathrm{mL}{ }^{-1}\right)\right.$ in $\mathrm{PBS}$ solution (10 mM, pH $\left.=8.0\right)$, $\left(\lambda_{\mathrm{Ex}}\right.$ $=315 \mathrm{~nm}, \lambda_{\mathrm{Em}}=614 \mathrm{~nm}$ ). (B) Phosphorescence spectra of $30 \mu \mathrm{g} \mathrm{mL}{ }^{-1} \mathrm{CaTiO}_{3}: \mathrm{Pr}^{3+} \mathrm{aSiO}_{2}$ with (red curve) and without (black curve) $200 \mu \mathrm{M} \mathrm{TNP}$. Inset: temporal change in the phosphorescence intensity of $\mathrm{CaTiO}_{3}: \mathrm{Pr}^{3+}(\mathrm{aSiO} 2$ after the addition of TNP. Effect of (C) pH and (D) salt concentration on the phosphorescence intensity of $\mathrm{CaTiO}_{3}: \mathrm{Pr}^{3+}\left(\mathrm{aSiO}_{2}\left(30 \mu \mathrm{gL}^{-1}\right)\right.$ in the absence (black line) and presence (red line) of $200 \mu \mathrm{M}$ TNP. $\lambda_{\mathrm{Ex}}=315 \mathrm{~nm}$ (error bars, SD, $n=3$ ).

phosphorescence intensity of $\mathrm{CaTiO}_{3}: \mathrm{Pr}^{3+}$ nanoparticles at $x=$ $0.4 \%$ was the highest in those red phosphorescence materials with different mole ratios of $\mathrm{Pr}^{3+}$. The sample sintered at $900{ }^{\circ} \mathrm{C}$ for $3 \mathrm{~h}$ showed the maximum phosphorescence intensity in Fig. S1B. $\dagger$ Here, the samples used in the later measurements were prepared at $\mathrm{Pr}^{3+}$ mole ratio $0.4 \%$, calcination temperature $900{ }^{\circ} \mathrm{C}$ and calcination time $3 \mathrm{~h}$. We also investigated the phosphorescence behavior of $\mathrm{CaTiO}_{3}: \mathrm{Pr}^{3+}$ before and after coated a silica shell. The phosphorescence intensity of $\mathrm{CaTiO}_{3}: \mathrm{Pr}^{3+}$ decreased after coated a silica shell (Fig. S2A $\dagger$ ), but the phosphorescence intensity of $\mathrm{CaTiO}_{3}: \mathrm{Pr}^{3+} @ \mathrm{SiO}_{2}$ hardly changed within $2 \mathrm{~h}$ under $315 \mathrm{~nm}$ excitation. Compared with the $\sim 30 \%$ decrease in phosphorescence intensity of $\mathrm{CaTiO}_{3}: \mathrm{Pr}^{3+}$ in about $2 \mathrm{~h}$ (Fig. $\mathrm{S} 2 \mathrm{~B} \dagger$ ), it can be inferred that the $\mathrm{CaTiO}_{3}$ :$\mathrm{Pr}^{3+} @ \mathrm{SiO}_{2}$ nanoparticles had better photo-stability than $\mathrm{CaTiO}_{3}: \mathrm{Pr}^{3+}$. $\mathrm{CaTiO}_{3}: \mathrm{Pr}^{3+} @ \mathrm{SiO}_{2}$ nanoparticles were used in later experiments.

The micromorphology analysis of $\mathrm{CaTiO}_{3}: \mathrm{Pr}^{3+} @ \mathrm{SiO}_{2}$ nanoparticles were carried out using scanning electron microscopy (SEM). As showed in Fig. 1A, $\mathrm{CaTiO}_{3}: \mathrm{Pr}^{3+} @ \mathrm{SiO}_{2}$ nanoparticles were uniformly dispersed with diameters of $115-300 \mathrm{~nm}$, and the average size was $201 \mathrm{~nm}$ (inset of Fig. 1A). Fig. 1B showed the diffraction peak positions and the relative intensities of
$\mathrm{CaTiO}_{3}: \mathrm{Pr}^{3+}$ and $\mathrm{CaTiO}_{3}: \mathrm{Pr}^{3+} @ \mathrm{SiO}_{2}$, respectively. The discernible five diffraction peaks could be indexed to (112), (220), (312), (224) and (332), which matched well with the database of perovskite in JCPDS (JCPDS Card no. 01-081-0561) file. The same position of characteristic peaks for $\mathrm{CaTiO}_{3}: \mathrm{Pr}^{3+}$ and $\mathrm{CaTiO}_{3}: \mathrm{Pr}^{3+} @ \mathrm{SiO}_{2}$ indicated the stability of the crystalline phase of $\mathrm{CaTiO}_{3}: \mathrm{Pr}^{3+}$ nanoparticles during silica coating. Besides the peak of $\mathrm{CaTiO}_{3}$, the XRD pattern of $\mathrm{CaTiO}_{3}$ :$\mathrm{Pr}^{3+} @ \mathrm{SiO}_{2}$ (red line) presented abroad XRD peak at low diffraction angle $\sim 21^{\circ}$, which attributed to the amorphous state $\mathrm{SiO}_{2}$ shells. Moreover, EDS elemental mapping images presented in Fig. $\mathrm{S} 3 \dagger$ verify the presence of $\mathrm{O}, \mathrm{Si}, \mathrm{Ca}$ and $\mathrm{Ti}$ elements in $\mathrm{CaTiO}_{3}: \mathrm{Pr}^{3+} @ \mathrm{SiO}_{2}$.

\section{Phosphorescence sensing to TNP}

Upon $315 \mathrm{~nm}$ excitation, a very intense single red emission band at $614 \mathrm{~nm}$ was found in the phosphorescence spectrum of $\mathrm{CaTiO}_{3}: \mathrm{Pr}^{3+} @ \mathrm{SiO}_{2}$ (Fig. 2A), corresponding to the characteristic ${ }^{1} \mathrm{D}_{2} \rightarrow{ }^{3} \mathrm{H}_{4}$ transition of $\mathrm{Pr}^{3+} .{ }^{28}$ The phosphorescence intensity was significantly quenched by $\sim 80 \%$ with the addition of 200 $\mu \mathrm{M}$ TNP (Fig. 2B). The response time for $\mathrm{CaTiO}_{3}: \mathrm{Pr}^{3+} @ \mathrm{SiO}_{2}$ toward TNP was within 1 min (the inset of Fig. $2 \mathrm{~B}$ ). 

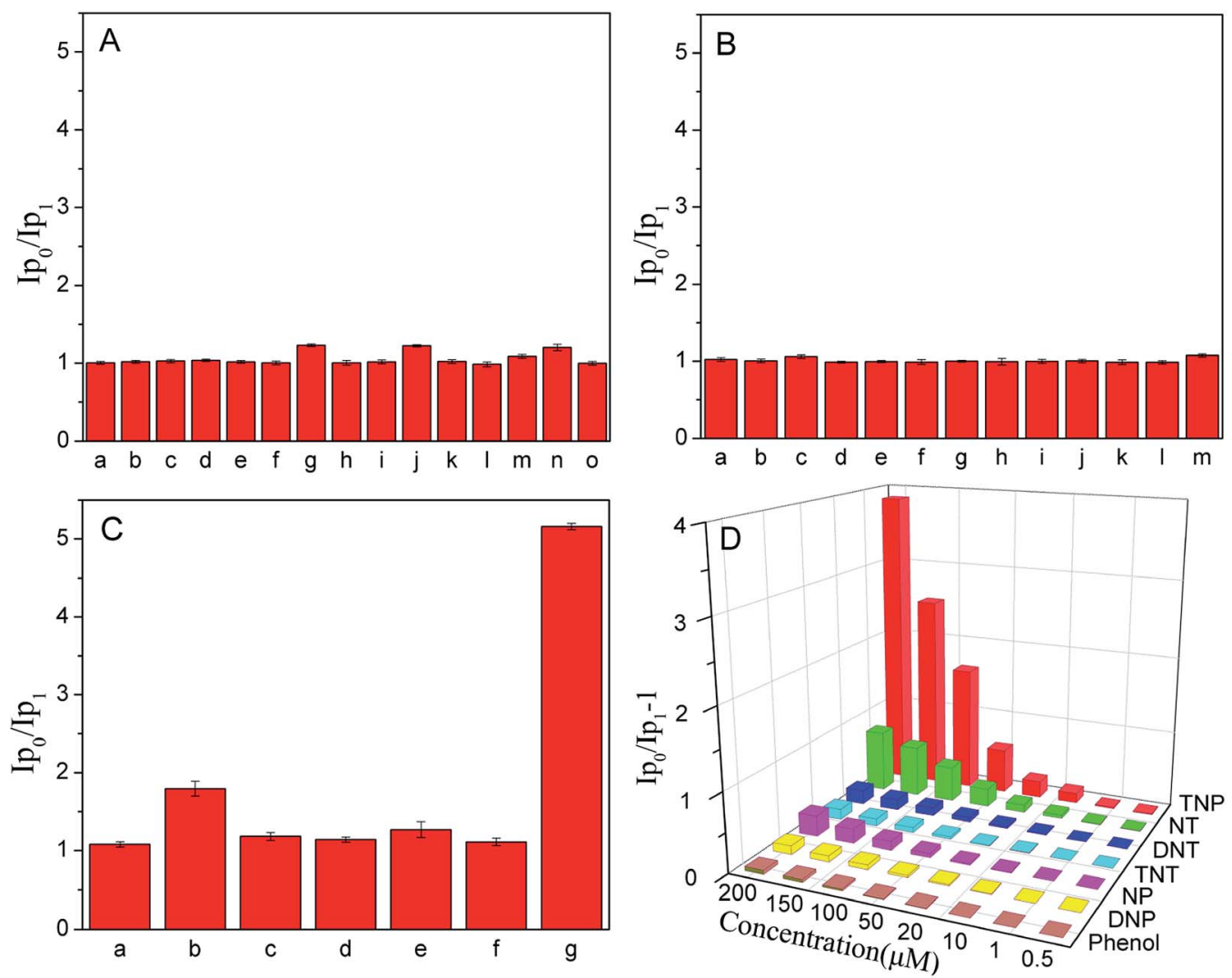

Fig. 3 (A-C) Relative phosphorescence intensities $\left(/ \mathrm{p}_{0} / / \mathrm{p}_{1}\right)$ of $\mathrm{CaTiO}_{3}: \mathrm{Pr}^{3+} \mathrm{aSiO}_{2}\left(30 \mu \mathrm{g} \mathrm{mL}^{-1}\right)$ to $200 \mu \mathrm{M}$ possible interfering substance in $\mathrm{PBS}$ solution (10 mM, pH= 8.0). (A): (a) $\mathrm{Na}^{+}$, (b) $\mathrm{Mg}^{2+}$, (c) $\mathrm{Al}^{3+}$, (d) $\mathrm{Ca}^{2+}$, (e) $\mathrm{Cr}^{3+}$, (f) $\mathrm{Mn}^{2+}$, (g) $\mathrm{Fe}^{3+}$, (h) $\mathrm{Co}^{2+}$, (i) $\mathrm{Ni}^{2+}$, (j) $\mathrm{Cu}^{2+}$, (k) $\mathrm{Zn}^{2+}$, (l) $\mathrm{Cd}^{2+}$, (m) $\mathrm{Ag}^{+}$, (n) $\mathrm{Hg}^{2+}$, (o) $\mathrm{Pb}^{2+}$. (B): (a) $\mathrm{F}^{-}$, (b) $\mathrm{Cl}^{-}$, (c) $\mathrm{Br}^{-}$, (d) I $\mathrm{I}^{-}$, (e) $\mathrm{CO}_{3}{ }^{2-}$, (f) oxalate, (g) citrate, (h) $\mathrm{NO}_{3}^{-}$, (i) $\mathrm{NO}_{2}{ }^{-}$, (g) $\mathrm{SO}_{4}{ }^{2-}$, (k) $\mathrm{SO}_{3}{ }^{2-}$, (l) $\mathrm{S}^{2-}$, (m) $\mathrm{PO}_{4}{ }^{3-}$. (C): (a) Phenol, (b) NT, (c) DNT, (d) TNT, (e) NP, (f) DNP, (g) TNP. (D): Phosphorescence quenching efficiencies $\left(\left(/ p_{0} / / p_{1}\right)-1\right)$ obtained from different nitroaromatic explosives. Where $/ p_{1}$ and $/ p_{0}$ were the phosphorescence intensity of $\mathrm{CaTiO}_{3}: \mathrm{Pr}^{3+} \mathrm{aSiO}_{2}$ with and without these possible interfering substance. $\lambda_{\mathrm{Ex}}=315 \mathrm{~nm}$ (error bars, SD, $n=3$ ).

The phosphorescence behavior of $\mathrm{CaTiO}_{3}: \mathrm{Pr}^{3+} @ \mathrm{SiO}_{2}$ in absence and presence of $200 \mu \mathrm{M}$ TNP in various PBS buffer at pH 2-12 were measured (Fig. 2C). The phosphorescence intensity of $\mathrm{CaTiO}_{3}: \mathrm{Pr}^{3+} @ \mathrm{SiO}_{2}$ in the absence of TNP was slowly raised in the $\mathrm{pH}$ range from 2 to 8 , and was comparatively stable when $\mathrm{pH}>8$. The phosphorescence intensity of $\mathrm{CaTiO}_{3}$ :$\mathrm{Pr}^{3+} @ \mathrm{SiO}_{2}$ was comparatively stable in the presence of TNP in the whole $\mathrm{pH}$ range from 2 to 12 . Considering the more stable phosphorescence intensity of $\mathrm{CaTiO}_{3}: \mathrm{Pr}^{3+} @ \mathrm{SiO}_{2}$ without TNP in the in the $\mathrm{pH}$ range from 8 to 12 , a weak alkaline condition of pH 8.0 (PBS, $10 \mathrm{mM}$ ) was used for the later phosphorescence measurements.

The phosphorescence intensity of $\mathrm{CaTiO}_{3}: \mathrm{Pr}^{3+} @ \mathrm{SiO}_{2}$ in the absence and presence of $200 \mu \mathrm{M}$ TNP remained almost constant when exposed to $0-100 \mathrm{mM} \mathrm{NaCl}$ solution (Fig. 2D), indicating that ionic strength just had negligible effect on the detection of TNP. The dramatic phosphorescence intensity decrease, short response time and stable phosphorescence behavior in wide $\mathrm{pH}$ range and high ionic strength demonstrated the great potential of $\mathrm{CaTiO}_{3}: \mathrm{Pr}^{3+} @ \mathrm{SiO}_{2}$ nanoparticles as effective TNP probe.

\section{Specificity of $\mathrm{CaTiO}_{3}: \mathrm{Pr}^{3+} @ \mathrm{SiO}_{2}$ toward TNP}

To verify the specific recognition of $\mathrm{CaTiO}_{3}: \mathrm{Pr}^{3+} @ \mathrm{SiO}_{2}$ to TNP, we investigated the phosphorescence behavior of $\mathrm{CaTiO}_{3}$ :$\mathrm{Pr}^{3+} @ \mathrm{SiO}_{2}$ to different metal ions $(200 \mu \mathrm{M})$, anions $(200 \mu \mathrm{M})$ and nitroaromatic explosives $(200 \mu \mathrm{M})$ in $\mathrm{PBS}(10 \mathrm{mM}, \mathrm{pH} 8.0)$. As showed in Fig. 3, the phosphorescence intensity of $\mathrm{CaTiO}_{3}: \mathrm{Pr}^{3+} @ \mathrm{SiO}_{2}$ had no obvious change in the presence of the above mentioned substances except that only several nitroaromatic explosives induced a negligible phosphorescence intensity decrease. The quenching efficiency for various

Table 1 Phosphorescence quenching constant $\left(K_{\mathrm{S}-\mathrm{v}}\right)$ values for different nitro explosives

\begin{tabular}{lll}
\hline Analytes & $K_{\mathrm{S}-\mathrm{V}}$ values $\left(\times 10^{4}\right)$ & Correlation coefficient $\left(R^{2}\right)$ \\
\hline TNP & 1.25 & 0.999 \\
NT & 0.41 & 0.992 \\
DNT & 0.090 & 0.991 \\
TNT & 0.067 & 0.995 \\
NP & 0.13 & 0.993 \\
DNP & 0.053 & 0.994 \\
Phenol & 0.025 & 0.995
\end{tabular}



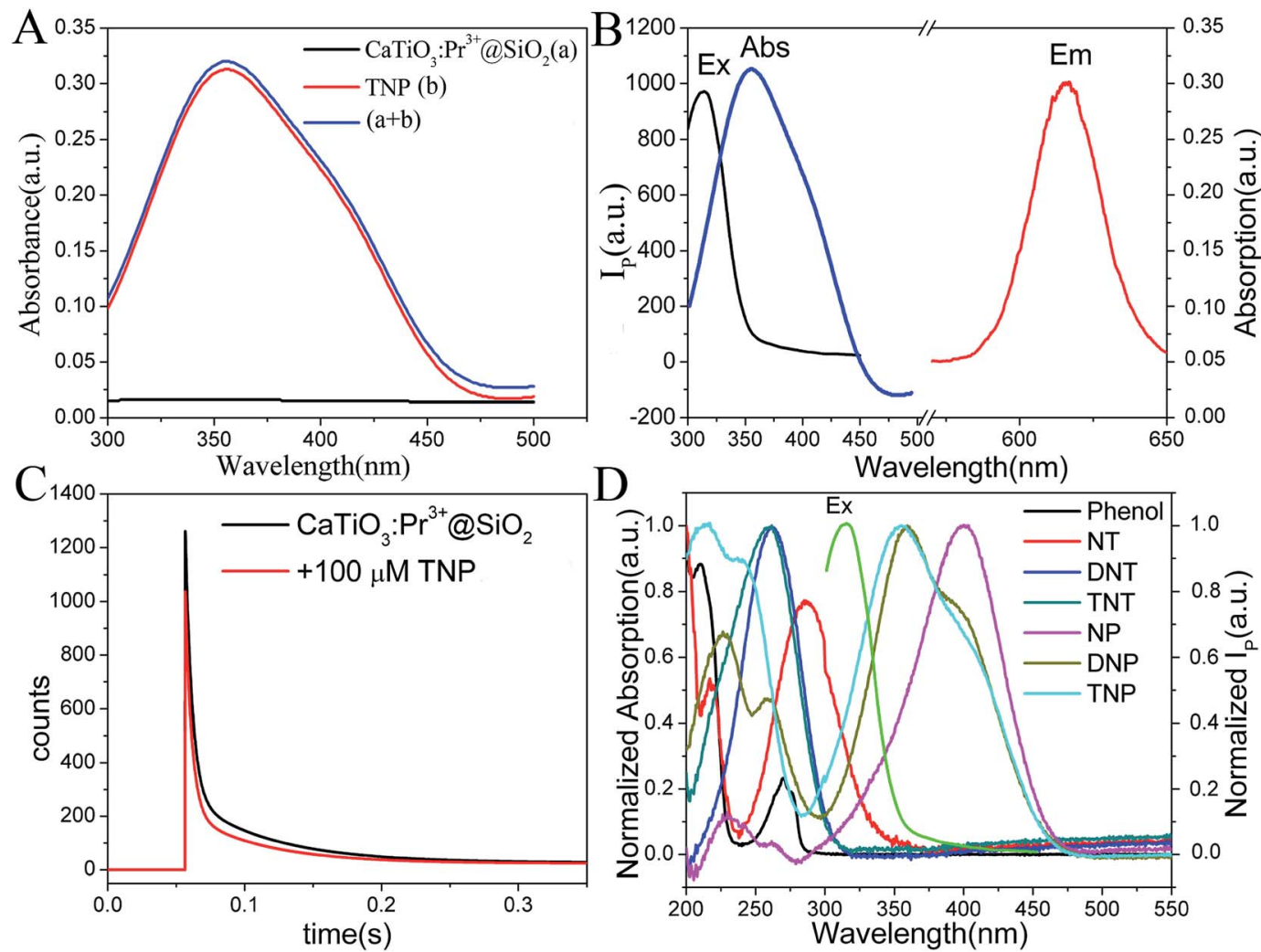

Fig. 4 (A) UV-vis absorption spectra of $\mathrm{CaTiO}_{3}: \mathrm{Pr}^{3+} \mathrm{aSiO}_{2}$ and TNP, and the sum of $\mathrm{CaTiO}_{3}: \mathrm{Pr}^{3+} \mathrm{aSiO}_{2}$ and TNP. (B) UV-vis absorption spectrum of TNP and the phosphorescence excitation and emission spectra of $\mathrm{CaTiO}_{3}: \mathrm{Pr}^{3+} \mathrm{aSiO}_{2}$. (C) Time-resolved decay of $\mathrm{CaTiO}_{3}: \mathrm{Pr}^{3+} \mathrm{aSiO}_{2}$ with and without $100 \mu$ M TNP. (D) Spectral overlap between excitation spectrum of $\mathrm{CaTiO}_{3}: \mathrm{Pr}^{3+} \mathrm{aSiO}_{2}$ and absorption spectra of different nitroexplosive compounds in PBS solution (10 $\mathrm{mM}, \mathrm{pH}=8.0)$.

nitroaromatic explosives (2,4,6-trinitrotoluene (TNT), 2,4-dinitrotoluene (DNT), 2-nitrotoluene (NT), 2,4-dinitrophenol (DNP), 4-nitrophenol (NP) and phenol) was also estimated by using the Stern-Volmer (SV) equation,

$$
I_{0} / I=1+K_{\mathrm{Sv}}[\mathrm{Q}]
$$

where $I_{0}$ and $I$ are phosphorescence intensities in the absence and presence of nitro explosive, $[\mathrm{Q}]$ is the molar concentration of analytes and $K_{\mathrm{SV}}$ is the quenching constant $\left(\mathrm{M}^{-1}\right)$. The quenching constants were shown in Table 1 . The $K_{\mathrm{SV}}$ of TNP was found to be $1.25 \times 10^{4} \mathrm{M}^{-1}$, which was much larger than other nitro aromatics, suggesting the predominant selectivity of $\mathrm{CaTiO}_{3}: \mathrm{Pr}^{3+} @ \mathrm{SiO}_{2}$ toward TNP. Another important feature of $\mathrm{CaTiO}_{3}: \mathrm{Pr}^{3+} @ \mathrm{SiO}_{2}$ was its high selectivity toward TNP in a competitive environment. The competitive experiments were conducted in the presence of TNP and various other metal ions, anions and nitroaromatic explosives. The results shown in Fig. $S 4 \uparrow$ displayed that there were no distinct variations of the phosphorescence signal caused by the coexistence of these species.

\section{Investigation of the detection mechanism}

In order to probe the origin of the high selectivity of $\mathrm{CaTiO}_{3}$ :$\mathrm{Pr}^{3+} @ \mathrm{SiO}_{2}$ toward TNP, the quenching process was studied. In general, as shown in Fig. 4A, the UV-vis absorption spectrum of the sum of $\mathrm{CaTiO}_{3}: \mathrm{Pr}^{3+} @ \mathrm{SiO}_{2}$ and TNP was very similar to that of TNP alone except a slight difference in the intensity. This phenomenon indicated that the no Meisenheimer complexes between $\mathrm{CaTiO}_{3}: \mathrm{Pr}^{3+} @ \mathrm{SiO}_{2}$ and TNP were formed. ${ }^{41}$ As shown in Fig. S5 in the ESI, $\dagger$ no new absorption peak but increased absorption intensity could be observed with the increasing concentration of TNP. These results excluded the possibility of a charge-transfer mechanism between TNP and $\mathrm{CaTiO}_{3}$ :$\mathrm{Pr}^{3+} @ \mathrm{SiO}_{2}$. As displayed in Fig. 4C, the photoluminescence lifetime of $\mathrm{CaTiO}_{3}: \mathrm{Pr}^{3+} @ \mathrm{SiO}_{2}$ in the absence and presence of $100 \mu \mathrm{M}$ TNP remained nearly constant, and the phosphorescence decay was fitted using a two-exponential decay function to yield a lifetime of $0.016 \mathrm{~s}$. The unchanged lifetime excluded the possibility of the FRET process between $\mathrm{CaTiO}_{3}: \mathrm{Pr}^{3+} @ \mathrm{SiO}_{2}$ and TNP. Fig. 4B showed the excitation spectrum and emission spectrum of $\mathrm{CaTiO}_{3}: \mathrm{Pr}^{3+} @ \mathrm{SiO}_{2}$ and the absorption spectrum of TNP. An obvious overlap between the excitation spectrum of $\mathrm{CaTiO}_{3}: \mathrm{Pr}^{3+} @ \mathrm{SiO}_{2}$ and the absorption spectrum of TNP can be noticed. Owing to the strong absorption of TNP, the excitation light for $\mathrm{CaTiO}_{3}: \mathrm{Pr}^{3+} @ \mathrm{SiO}_{2}$ was weakened by an inner filter effect (IFE) process. Therefore, the IFE could be considered as one major process in the phosphorescence quenching behavior of the $\mathrm{CaTiO}_{3}: \mathrm{Pr}^{3+} @ \mathrm{SiO}_{2}$ after addition of TNP. As comparison, there were little overlap between the UV-vis absorption spectra 


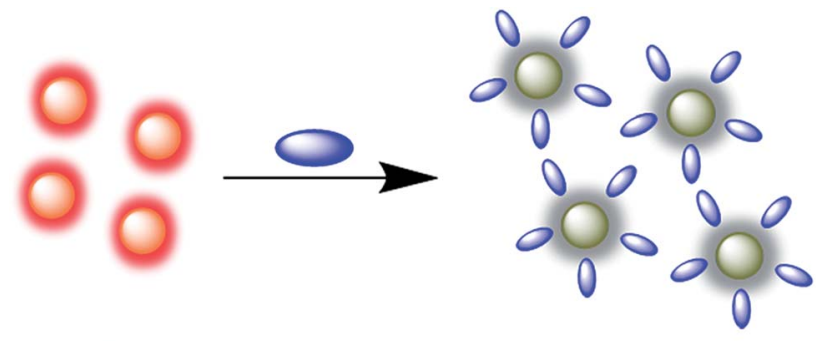

$$
\text { O: } \mathrm{CaTiO}_{3}: \mathrm{Pr}^{3+} @ \mathrm{SiO}_{2} \mathrm{O}: \mathrm{TNP}
$$

Scheme 1 Scheme for the phosphorescence quenching detection of TNP based on the $\mathrm{CaTiO}_{3}: \mathrm{Pr}^{3+} \mathrm{aSiO}_{2}$ photoluminescence materials.

of the other six nitroaromatic explosives and the phosphorescence excitation spectrum of $\mathrm{CaTiO}_{3}: \mathrm{Pr}^{3+} @ \mathrm{SiO}_{2}$, which resulted in poor IFE efficiency (Fig. 4D). On the other hand, we supplemented the FT-IR spectra of $\mathrm{CaTiO}_{3}: \mathrm{Pr}^{3+} @ \mathrm{SiO}_{2}, \mathrm{TNP}, \mathrm{CaTiO}_{3}$ :$\mathrm{Pr}^{3+} @ \mathrm{SiO}_{2}$ and TNP mixture, respectively, and the results were presented in Fig. S6. $\dagger$ Comparing line $\mathrm{b}$ and line $\mathrm{c}$, the band at $1275 \mathrm{~cm}^{-1}$ responsible for $\mathrm{C}-\mathrm{N}$ stretching, at $1155 \mathrm{~cm}^{-1}$ for $\mathrm{C}-\mathrm{O}$ bond stretching, at $1350 \mathrm{~cm}^{-1}$ for $-\mathrm{NO}_{2}$ group symmetric stretching and at $1525 \mathrm{~cm}^{-1}$ for asymmetric stretching were all hardly shifted, which suggested that there were no chemical bond was formed between $\mathrm{CaTiO}_{3}: \mathrm{Pr}^{3+} @ \mathrm{SiO}_{2}$ and TNP. ${ }^{42,43}$ Besides, we also tested the $\zeta$-potential of $\mathrm{CaTiO}_{3}: \mathrm{Pr}^{3+} @ \mathrm{SiO}_{2}$ alone and $\mathrm{CaTiO}_{3}: \mathrm{Pr}^{3+} @ \mathrm{SiO}_{2}$ with NP, DNP and TNP, As showed in Fig. $\mathrm{S} 7, \uparrow$ the average $\zeta$-potential of $\mathrm{CaTiO}_{3}: \mathrm{Pr}^{3+} @ \mathrm{SiO}_{2}$ alone, $\mathrm{CaTiO}_{3}: \mathrm{Pr}^{3+} @ \mathrm{SiO}_{2}$ with NP, DNP and TNP were $-22 \mathrm{mV}$, $-23.9 \mathrm{mV},-14.8 \mathrm{mV}$ and $-8.29 \mathrm{mV}$ respectively, which meant that the electrostatic interaction between $\mathrm{CaTiO}_{3}: \mathrm{Pr}^{3+} @ \mathrm{SiO}_{2}$ and TNP was higher than that with DNP and NP. As mentioned above, the unprecedented selectivity of $\mathrm{CaTiO}_{3}: \mathrm{Pr}^{3+} @ \mathrm{SiO}_{2}$ toward TNP can be explained by the favorable IFE and electrostatic interactions. Scheme 1 showed the possible mechanism of the phosphorescence quenching detection of TNP based on the $\mathrm{CaTiO}_{3}: \mathrm{Pr}^{3+} @ \mathrm{SiO}_{2}$ photoluminescence materials.

\section{Detection of TNP by $\mathrm{CaTiO}_{3}: \mathrm{Pr}^{3+} @ \mathrm{SiO}_{2}$}

According to the above investigation, we found that the phosphorescence intensity decreased with the increasing of TNP, when $\mathrm{CaTiO}_{3}: \mathrm{Pr}^{3+} @ \mathrm{SiO}_{2}$ were free in aqueous solution under UV light off instantaneously, strong red phosphorescence can be observed (Fig. 5A-a). However, in the presence of TNP, the phosphorescence of $\mathrm{CaTiO}_{3}: \mathrm{Pr}^{3+} @ \mathrm{SiO}_{2}$ was quenched significantly (Fig. 5A-b), indicated that $\mathrm{CaTiO}_{3}: \mathrm{Pr}^{3+} @ \mathrm{SiO}_{2}$ possed good TNP response ability. Therefore, in order to exploring the sensing ability of $\mathrm{CaTiO}_{3}: \mathrm{Pr}^{3+} @ \mathrm{SiO}_{2}$ to TNP, phosphorescence quenching titrations were performed with incremental additions of TNP to $\mathrm{CaTiO}_{3}: \mathrm{Pr}^{3+} @ \mathrm{SiO}_{2}$. Fig. 5A showed the quenching of phosphorescence intensity upon the addition of TNP solutions $(0-300 \mu \mathrm{M})$. The phosphorescence intensity gradually decreased with increasing concentrations of TNP and then reached a plateau when TNP concentration reached 300 $\mu \mathrm{M}$ (Fig. 5B). The maximum phosphorescence intensity of $\mathrm{CaTiO}_{3}: \mathrm{Pr}^{3+} @ \mathrm{SiO}_{2}$ was reduced by when TNP concentration reached $300 \mu \mathrm{M}$ (Fig. 5B). The maximum phosphorescence intensity of $\mathrm{CaTiO}_{3}: \mathrm{Pr}^{3+}$ @SiO${ }_{2}$ was reduced by $88.2 \%$ upon exposure to $300 \mu \mathrm{M}$ TNP solution. A good linear relationship between phosphorescence signal of $\left(I \mathrm{p}_{0} / I \mathrm{p}_{1}\right)$ and TNP concentration was observed from 0.5 to $100 \mu \mathrm{M}\left(R^{2}=0.998\right)$, with a limit of detection of $20.6 \mathrm{nM}$. Compared with other systems for ATP detection (Table S1†), our $\mathrm{CaTiO}_{3}: \mathrm{Pr}^{3+} @ \mathrm{SiO}_{2}$ phosphorescence sensor showed lower detection limit and wider linear range.

\section{Determining the concentration of TNP in water samples}

To illustrate the feasibility of the phosphorescence TNP sensor in complex matrices, the proposed method was applied in the detection of TNP in pond water samples. The water samples
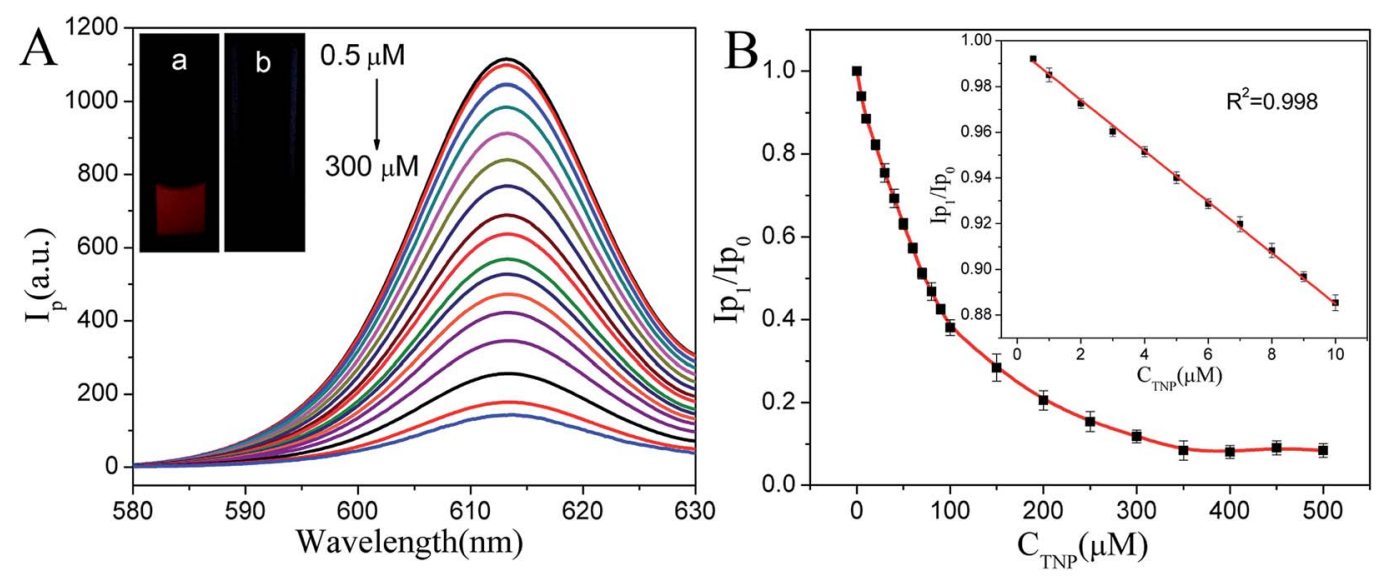

Fig. 5 (A) Phosphorescence spectra of $\mathrm{CaTiO}_{3}: \mathrm{Pr}^{3+}\left(\mathrm{aSiO}_{2}\left(30 \mu \mathrm{g} \mathrm{mL}^{-1}\right)\right.$ upon addition of increasing concentrations of TNP $(0.5 \mu M-300 \mu M)$ in PBS buffer (pH 8.0, $10 \mathrm{mM}$ ). Inset: the photograph of the $\mathrm{CaTiO}_{3}: \mathrm{Pr}^{3+} \mathrm{aSiO}_{2}$ without (a) and with (b) TNP under UV light off instantaneously. (B) The plot of the value of relative phosphorescence intensities $\left(/ \mathrm{p}_{0} / / \mathrm{p}_{1}\right)$ versus the concentration of TNP in PBS buffer (10 mM, pH 8.0). Inset: the linear relationship of relative phosphorescence intensities $\left(/ \mathrm{p}_{0} / / \mathrm{p}_{1}\right)$ versus the concentration of TNP over the range from $0.5 \mu \mathrm{M}$ to $300 \mu \mathrm{M}$. Where $/ \mathrm{p}_{1}$ and $/ \mathrm{p}_{\mathrm{O}}$ were the phosphorescence intensity of $\mathrm{CaTiO}_{3}: \mathrm{Pr}^{3+} \mathrm{aSiO}_{2}$ with and without TNP. $\lambda_{\mathrm{Ex}}=315 \mathrm{~nm}$ (error bars, SD, $n=3$ ). 
were transferred to a centrifuge tube and the large particles were separated from the water by centrifugation at $10000 \mathrm{rpm}$ for $15 \mathrm{~min}$. The reliability and accuracy of the detection method we developed were evaluated through a recovery study, which was carried out on samples spiked with standard TNP solutions $(20,50,80 \mu \mathrm{M})$. The results were satisfactory with the recoveries of $99.34-101.6 \%$ (Table $\mathrm{S} 2 \dagger$ ), indicating potential applications in the detection of TNP in pond water.

\section{Conclusions}

In summary, highly photoluminescent $\mathrm{CaTiO}_{3}: \mathrm{Pr}^{3+} @ \mathrm{SiO}_{2}$ nanoparticles were synthesized through a solid-state synthesis method, which can act as a sensitive and selective phosphorescent chemosensor for the detection of TNP in aqueous solution without interference from different metal ions, anions and nitroaromatic explosives. As a phosphorescence probe, $\mathrm{CaTiO}_{3}: \mathrm{Pr}^{3+} @ \mathrm{SiO}_{2}$ has better physical and chemical stabilities, long phosphorescence lifetime and eco-friendliness. The phosphorescence intensity gradually decreased with increasing concentrations of TNP. A good linear relationship between the phosphorescence and TNP concentration was obtained from 0.5 to $100 \mu \mathrm{M}$, and the detection limit was as low as $20.6 \mathrm{nM}$. The IFE and electrostatic interactions were considered to be the main process for the photoluminescence responses for this sensor system. The chemosensor was successfully used to determine the concentration of TNP in water samples, which made it possible for rapid, convenient, sensitive, and selective detection of trace amounts of TNP in environmental and water samples. On conclusion, the developed method is expected to be further applied in environmental pollution analysis.

\section{Conflicts of interest}

There are no conflicts to declare.

\section{Acknowledgements}

The work described in this paper was supported by the National Natural Science Foundation of China (21377089, 21407109). We would like to express our sincere thanks to Analytical \& Testing Centre of Sichuan University for the measurements.

\section{References}

1 Y. Peng, A. J. Zhang, M. Dong and Y. W. Wang, Chem. Commun., 2011, 47, 4505-4507.

2 G. He, H. Peng, T. Liu, M. Yang, Y. Zhang and Y. Fang, J. Mater. Chem., 2009, 19, 7347-7353.

3 P. Ghosh, S. K. Saha, A. Roychowdhury and P. Banerjee, Eur. J. Inorg. Chem., 2015, 17, 2851-2857.

4 P. Ghosh and P. Banerjee, Anal. Chim. Acta, 2017, 965, 111122.

5 M. Dong, Y. W. Wang, A. J. Zhang and Y. Peng, Chem.-Asian J., 2013, 8, 1321-1330.

6 D. Singha, S. Bhattacharya, P. Majee, S. Mondal, M. Kumar and P. Mahata, J. Mater. Chem. A, 2014, 2, 20908-20915.
7 M. Rong, L. Lin, X. Song, T. Zhao, Y. Zhong, J. Yan, Y. Wang and X. Chen, Anal. Chem., 2015, 87, 1288-1296.

8 Y. Salinas, R. Martinez-Manez, M. D. Marcos, F. Sancenon, A. M. Costero, M. Parra and S. Gil, Chem. Soc. Rev., 2012, 41, 1261-1296.

9 M. E. Germain and M. J. Knapp, Chem. Soc. Rev., 2009, 38, 2543-2555.

10 J. S. Yang and T. M. Swager, J. Am. Chem. Soc., 1998, 120, 11864-11873.

11 B. Xu, X. Wu, H. Li, H. Tong and L. Wang, Macromolecules, 2011, 44, 5089-5092.

12 Y. Ma, H. Li, S. Peng and L. Wang, Anal. Chem., 2012, 84, 8415-8421.

13 V. Bhalla, A. Gupta, M. Kumar, D. S. Rao and S. K. Prasad, ACS Appl. Mater. Interfaces, 2013, 5, 672-679.

14 S. Babaee and A. Beiraghi, Anal. Chim. Acta, 2010, 662, 9-13. 15 M. López-López and C. García-Ruiz, TrAC, Trends Anal. Chem., 2014, 54, 36-44.

16 D. S. Moore, Rev. Sci. Instrum., 2004, 75, 2499-2512.

17 R. Mu, H. Shi, Y. Yuan, A. Karnjanapiboonwong, J. G. Burken and Y. Ma, Anal. Chem., 2012, 84, 3427-3432.

18 K. Badjagbo and S. Sauvé, Crit. Rev. Anal. Chem., 2012, 42, 257-271.

19 J. M. Sylvia, J. A. Janni, J. D. Klein, K. M. Spencer and A. Chem, Anal. Chem., 2000, 72, 5834-5840.

20 R. Hodyss and J. L. Beauchamp, Anal. Chem., 2005, 77, 36073610.

21 P. Ghosh, S. Paul and P. Banerjee, CrystEngComm, 2017, 19, 6703-6710.

22 P. Ghosh, J. Das, A. Basak, S. K. Mukhopadhyay and P. Banerjee, Sens. Actuators, B, 2017, 251, 985-992.

23 Q. Zhao, C. Huang and F. Li, Chem. Soc. Rev., 2011, 40, 25082524.

24 V. W. Yam and K. M. Wong, Chem. Commun., 2011, 47, 11579-11592.

25 L. He, J. Qiao, L. Duan, G. Dong, D. Zhang, L. Wang and Y. Qiu, Adv. Funct. Mater., 2009, 19, 2950-2960.

26 Y. Chi and P. T. Chou, Chem. Soc. Rev., 2010, 39, 638-655.

27 R. D. Costa, E. Ortí, H. J. Bolink, F. Monti, G. Accorsi and N. Armaroli, Angew. Chem., Int. Ed., 2012, 51, 8178-8211.

28 P. T. Diallo, P. Boutinaud, R. Mahiou and J. C. Cousseins, Phys. Status Solidi A, 2015, 160, 255-263.

29 Z. Pan, Y. Y. Lu and F. Liu, Nat. Mater., 2012, 11, 58-63.

30 W. Zeng, Y. Wang, S. Han, W. Chen, G. Li, Y. Wang and Y. Wen, J. Mater. Chem. C, 2013, 1, 3004-3011.

31 Y. Luo and Z. Xia, J. Phys. Chem. C, 2014, 118, 23297-23305.

32 R. Ali and M. Yashima, J. Solid State Chem., 2005, 178, 28672872.

33 H. J. A. Koopmans, G. M. H. V. D. Velde and P. J. Gellings, Acta Crystallogr., Sect. C: Cryst. Struct. Commun., 1983, 39, 1323-1325.

34 P. Boutinaud, L. Sarakha, E. Cavalli, M. Bettinelli, P. Dorenbos and R. Mahiou, J. Phys. D: Appl. Phys., 2009, 42, 45106-45112.

35 Y. Inaguma, T. Muronoi, K. Sano, T. Tsuchiya, Y. Mori, T. Katsumata and D. Mori, Inorg. Chem., 2011, 50, 53895395. 
36 B. Wang, H. Lin, J. Xu, H. Chen, Z. Lin, F. Huang and Y. Wang, Inorg. Chem., 2015, 54, 11299-11306.

37 X. Zhang, J. Zhang, X. Ren and X. J. Wang, J. Solid State Chem., 2008, 181, 393-398.

38 X. Zhang, J. Zhang, X. Zhang, M. Wang, H. Zhao, S. Lu and X. Wang, J. Phys. Chem. C, 2007, 111, 18044-18048.

39 K. Sue, S. Kawasaki, T. Sato, D. Nishiohamane, Y. Hakuta and T. Furuya, Ind. Eng. Chem. Res., 2016, 55, 7628-7634.
40 R. Chen and D. Chen, Spectrochim. Acta, Part A, 2014, 127, 256-260.

41 Y. Wang and Y. Ni, Anal. Chem., 2014, 86, 7463-7470.

42 P. Ghosh and P. Banerjee, Phys. Chem. Chem. Phys., 2016, 18, 22805-22815.

43 P. Ghosh, P. Roy, A. Ghosh, S. Jana, N. C. Murmu, S. K. Mukhopadhyay and P. Banerjee, J. Lumin., 2017, 185, 272-278. 